\title{
Анализ рентгеновских спектров дифракционного отражения для контроля параметров фотоприемных структур с множественными квантовыми ямами
}

\author{
Д.В. Ильинов, А.Д. Шабрин, Д.А. Пашкеев \\ АО «НПО «Орион», Москва, 111538, ул. Косинская, 9 \\ тел: +7 (499) 373-6011, эл. почта: dv.iljinov@physics.msu.ru
}

DOI 10.34077/RCSP2019-104

В настоящее время на основе гетероструктур с множественными квантовыми ямами успешно разрабатываются и изготавливаются матричные фотоприемные устройства [1]. Для улучшения их характеристик необходим прецизионный контроль параметров гетероструктуры. Неразрушающим методом исследования и контроля характеристик гетероструктур является метод рентгеновской дифрактометрии, однако спектры рентгеновского отражения от многослойных периодических структур имеют сложный вид и влияние дефектов трудно интерпретируемо [2]. Поэтому требуется изучение свойств спектров и влияния на них параметров гетероструктур с квантовыми ямами на основе новых подходов.

В основе метода высокоразрешающей рентгеновской дифрактометрии лежит измерение кривых качания. В них содержится основная информация о степени кристаллического совершенства и параметрах эпитаксиальных слоёв. В работе решается обратная задача дифракции: путем поочерёдного варьирования параметров структуры проводится численный расчет соответствующих

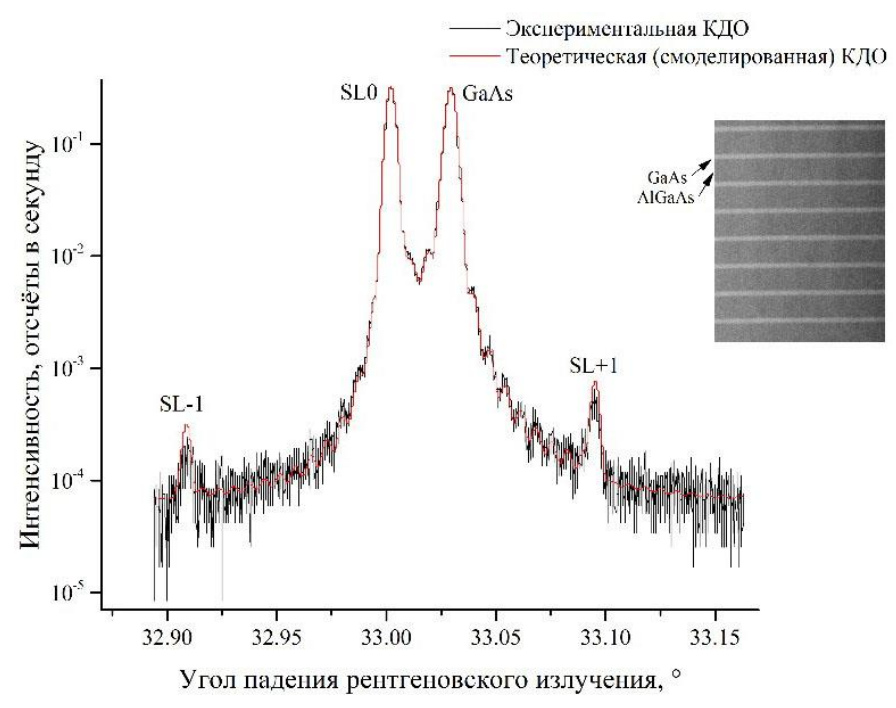
кривых качания и выявляются причины, влияющие на их изменения. В основу численной модели был заложен метод матрицы переноса в рамках динамической теории дифракции.

Рассчитаны кривые качания многослойных периодических гетероструктур $\mathrm{AlGaAs} / \mathrm{GaAs}$ в зависимости от толщин $d$, состава слоев $x$ и количества периодов $N$. Было установлено, что при фиксированных значения $d$ и $x$ барьера $\mathrm{Al}_{\mathrm{x}} \mathrm{Ga}_{1-\mathrm{x}} \mathrm{As}(25 \mathrm{нм}, \mathrm{x}=0,25)$ и ямы $\mathrm{GaAs}$ (5 нм) с увеличением числа периодов в гетероструктуре толщинные осцилляции и пики-сателлиты значительно проявляются к 10 периодам. Дальнейшее увеличение $N$ приводит к пропорциональному росту осцилляций и уменьшению их амплитуды. Амплитуда сателлитов увеличивается. Для $N>60$ амплитуда осцилляций сильно уменьшается и они становятся мало различимы. Изменение $x$ с 0,15 до 0,35 при фиксированных остальных параметрах приводит к смещению углового положения нулевого пика с $33,0154^{\circ}$ до $32,9968^{\circ}$. Количество сателлитов не изменяется, однако изменяется их угловое положение. С возрастанием $x$ сателлиты положительных порядков приближаются к пику подложки на величину порядка $0,02^{\circ}$, а сателлиты отрицательного порядка смещаются дальше от нулевого пика на ту же величину. Повышение толщины барьера AlGaAs c 15 нм до 35 нм (при фиксированных $x=0,26$ и $N=50$ ) приводит к увеличению интенсивности нулевого пика с 0,164 до 0,298 отсчетов в секунду, интенсивность максимума, соотвествующего GaAs, снижается с 0,332 до 0,294 отсчетов в секунду. А угловое положение сателлита 1 -го порядка $\theta_{1}$ изменилось на $0,1355^{\circ}$, а -1-го порядка $\theta-{ }_{1}$ - на $0,1264^{\circ}$.

Результаты численного анализа использованы при выращивании методом молекулярно-лучевой эпитаксии фотоприемных устройств с квантовыми ямами на основе гетеропары $\mathrm{AlGaAs} / \mathrm{GaAs}$. Ha рисунке приведены экспериментальная и расчетная кривые качания для структуры с 50 квантовыми ямами. По уточненным с помощью моделирования данным: доля алюминия $x=0,267$, средняя толщина квантовых барьеров и ям - 51,6 нм и 4,6 нм соответственно.

\section{Лuтература}

[1] A. Rogalski, P. Martyniuk, M. Kopytko. InAs/GaSb type-II superlattice infrared detectors: Future prospect. Applied physics reviews 4, 031304 (2017). http://dx.doi.org/10.1063/1.4999077.

[2] И.С. Васильевский и др. // Физика и техника полупроводников. 2014. Т.48, вып.9. С.1258-1264. 